\title{
POLÍTICAS PÚBLICAS PARA EDUCAÇÃO PENITENCIÁRIA NO BRASIL: PRIMEIRAS VERSÕES DOS PLANOS ESTADUAIS DE EDUCAÇÃO PARA OS SISTEMAS PENITENCIÁRIOS ${ }^{1}$
}

\author{
Eliane Leal V asquez. \\ Edmar Souza das Neves \\ Lucidéa Portal Melo de Carvalho \\ Zoar de Oliveira V asquez.
}

\section{INTRODUÇÃO}

Desde a segunda metade do século XIX no Brasil, a instrução escolar à população carcerária é mencionada no conteúdo de regulamentos penitenciários da Casa de Correção da Corte/Rio de Janeiro, Presídio de Fernando de Noronha, Casa de Correção de Porto Alegre, Colônia Correcional de Dois Reis, Casa de Correção de São Paulo e outras instituições destinadas ao cumprimento de penas.

Desse modo, a promoção da cultura escolar à pessoa presa antecede a Lei de Execução Penal. Nesse contexto é interessante observar que a inserção da instrução escolar na prisão ocorreu no Brasil Império, concomitante à organização da instrução pública.

Neste período da história das prisões no Brasil,

O "controle político da nação" esteve nas mãos de D. Pedro I e D. Pedro II entre 1822 a 1889, regido pelos princípios da Constituição Política do Império do Brasil. Durante o segundo reinado de 1840 a 1889 o país esteve organizado por meio dos Poderes Legislativo, Executivo, Judiciário e Moderador, sendo marcada pela economia cafeeira, difusão da instrução pública em nível primário, secundário e superior, construção de instituições prisionais e implantação de novos regulamentos penitenciários, como no caso da Casa de Correção da Corte, Casa de Correção de São Paulo, Casa de Correção de Porto Alegre e Presídio de Fernando de Noronha [...], tendo o término do governo de D. Pedro II, quase coincidindo com a abolição da escravatura (VASQUEZ, 2010, p. 55).

${ }^{1}$ DOI: $10.29388 / 978-65-86678-21-5-f .19-36$. 
No século XIX, de acordo com a análise de Foucault (1977), os estabelecimentos penais surgiram enquanto prisão-aparelho, isto é, instituição disciplinar destinada ao controle, à vigília e à punição do corpo do condenado, com base nos princípios que passaram a vigorar nessa época, as conhecidas técnicas penitenciárias. Essas técnicas se constituíram a partir dos princípios da correção, classificação, modulação da pena, trabalho como obrigação e direito, educação penitenciária, controle técnico da detenção e instituições anexas.

A prática do encarceramento nos países, implicou no ingresso da escola, da igreja e do hospital para o interior das prisões e a chegada de um corpo de funcionários que passaram a compor a administração penitenciária, como os capelães, os guardas, os médicos, os professores, os psiquiatras e os psicólogos (FOUCAULT, 1977).

\subsection{Revisão histórica da Educação Penitenciária no Brasil}

A Lei de Execução Penal - LEP de 1984 ratificou a presença das escolas nos estabelecimentos penais ao normatizar a obrigatoriedade do ensino de $1^{\circ}$ grau às pessoas presas e custodiadas. Como ainda do ensino profissional ao nível de iniciação ou técnico, bem como a organização de bibliotecas, pois revogou as normas gerais do regime penitenciário (GOMES, 2006; BRASIL, 1957).

Mas essas ideias não são inovadoras, pois desde o movimento de reforma das prisões no século XIX (VASQUEZ, 2013), considerando que já se defendia a instrução às pessoas presas e crianças na Europa, Brasil e outros países. Esta constatação verifica-se nos discursos dos regulamentos da Casa de Correção da Corte e Casa de Correção da Capital Federal, segundo Brasil (1850), Brasil (1882) e Brasil (1900):

Art. 167. Crear-se-há logo que for possível em cada huma das divisões da Casa de Correcção huma escola, onda se ensinará aos presos a ler e a escrever, e as quatro operações de arithmetica (apud ROIG, 2005, p. 209).

Art. 281. A instrucção escolar é confiada a um preceptor e dada simultaneamente aos presos, reunidos por classes na escola. [...]. Art. 285. O preceptor é ajudado pelo capellão no ensino moral, religião e regras de civilidade (apud ROIG, 2005, p. 251). 
Art. 187. A instrucção escolar é confiada a um professor e dada simultaneamente aos presos reunidos por classe na escola, todos os dias uteis (ROIG, 2005, p. 285).

E também em artigos do regulamento do Presídio de Fernando de Noronha:

Art. 7. Os Capellães dirão missa diariamente, ministrarão os soccorros espirituaes, e a instrucção religiosa aos presos e habitantes do presidio, por meio de predicas e outros exercicios, e o que fôr nomeado Professor de primeiras letras, dará lições todos os dias uteis de manhã e de tarde. O menos graduado ou o mais moderno dos Capellães será Coadjutor do mais antigo. [...]. Art. 14. A Professora de primeiras letras dará lições todos os dias uteis de manhã e de tarde a todas as meninas do Presidio (BRASIL, 1865).

Assim, já se defendia a presença da escola de primeiras letras nas prisões. A partir da segunda metade do século XIX, sabemos que a instrução escolar, moral e religiosa iniciou na Casa de Correção da Corte, Penitenciária de São Paulo e Presídio de Fernando de Noronha ${ }^{2}$ para pessoas presas e crianças, período em que seus dados eram informados aos Ministérios Justiça e Negócios Interiores e da Guerra. Enquanto no início do século XX, as instituições de ensino passaram a ser as escolas correcionais, conforme é esclarecido por Santos (2009) e Menezes (2009), a exemplo, da Escola Correcional de Dois Reis e Escola Correcional de Recife.

Já a partir da segunda metade do século XX, com a organização do ensino supletivo no Brasil, outras instituições passaram a atuar nos Estados e Distrito Federal, como as escolas da rede pública de ensino, que trabalhavam com a oferta de cursos de ensino supletivo, o que se tornou a modalidade de ensino, chamada Educação de Jovens e Adultos - EJA. De acordo com o Art. 73 da Lei de Diretrizes e Bases da Educação Nacional - LDBN, a EJA é "para àqueles que não tiveram acesso ou continuidade de estudos no ensino fundamental e médio na idade própria" (BRASIL, 1996).

São conhecidas algumas escolas públicas e outras instituições que atuam com educação formal nos sistemas penitenciários no Brasil, como: Funda-

\footnotetext{
${ }^{2}$ MORAES, E. Prisões e Instituições Penitenciarias no Brazil, p. 16; JAGUARY, V.; TOLENTINO, A. N.; FLEURY, A. A. P. et al. Relatorio da Commissão Inspectora da Casa de Correcção da Corte, p. 221; FLEURY, A. A. P., VILLAÇA, J. P., PESTANA, F. R. Relatorio da Commissão Inspectora da Penitenciaria, p. 17; NEVES, E. S. Tempo-Memória e Educação no Presídio Ilha de Fernando de Noronha: Aspectos históricos à luz da ciência penitenciária, p. 119-120.
} 
ção de Amparo ao Trabalhador Preso (São Paulo e Rio de Janeiro), Centros Estaduais de Educação Básica para Jovens e Adultos (Paraná), Centro de Estudos Supletivo Emílio Médici, Centro de Educação de Jovens e Adultos Emílio Médici, Escola Estadual São José (Amapá) e Escola Estadual Antônio Ferreira (Roraima) (JULIÃO, 2003; MOREIRA, 2008; CARVALHEIRO, 2010; ABREU, 2008; VASQUEZ, 2010; VASQUEZ; NEVES, 2012).

Com a mudança da concepção de educação na prisão de educação intelectual para educação integral e com sua inserção nos instrumentos do tratamento penitenciário (VASQUEZ, 2010), o que se observa nos discursos de regulamentos penitenciários na transição do século XIX ao XX. Além do surgimento da ciência penitenciária, do direito penitenciário e dos direitos humanos, a defesa da educação e das bibliotecas ganharam força no discurso de documentos em âmbito internacional e nacional.

Um exemplo disso é o caso do documento intitulado As Regras Minimas para o Tratamento de Prisioneiros, que foi elaborado no $1^{\circ}$ Congresso das Nações Unidas sobre Prevenção do Crime e Tratamento de Delinquentes (1955), que estabeleceu a garantia à educação nas prisões; bem como a Declaração de Hamburgo (1997), que expõe sobre o direito da educação das pessoas presas, afirmando a preocupação de estimular oportunidades de aprendizagem para todos, e ainda, as Regras Minimas para o Tratamento do Preso no Brasil (1994), que tratam das instruções e da assistência educacional no seu Capítulo XII (AÇÃO EDUCATIVA, 2006; BRASIL, 1994).

Ireland (2011), pesquisador que se dedica aos problemas da EJA, avalia com relação à educação para pessoas presas:

A educação para jovens e adultos em situação de privação de liberdade sofre de limitações similares às da EJA quando realizada em outros contextos. Entender a educação em prisões como parte integrante da educação de adultos é importante politicamente para reforçar políticas públicas e por ser parte de um movimento que tem potencial de trazer benefícios mais amplos. Ao mesmo tempo, no caso da educação em prisões, não há como se esquecer de que o processo educacional se dá no contexto de uma política de execução penal que, embora considerada "moderna" e exemplar, impõe questões específicas (IRELAND, 2011, p. 30-31).

O autor chama a atenção para o fato de quando nos referirmos à educação para pessoas presas, não esqueçamos que o assunto não só faz parte da Educação de Jovens e Adultos, mas também relaciona-se com questões específicas da política de execução penal (IRELAND, 2011). 
A educação penitenciária brasileira desenvolveu-se alicerçada em uma vasta legislação e obras de diferentes áreas do conhecimento. A temática se fortaleceu com a execução do Projeto Educando para Liberdade ${ }^{3}$, o que se verifica pelas publicações que surgiram a partir de 2007 , bem como pelos livros que foram publicados no Brasil até 2011, período que é o foco deste estudo.

Alguns dos livros publicados nesse período, foram os seguintes: Educação Escolar entre as Grades, organizado por Lourenço e Onofre (2007), Educação em Prisões: Direitos e Desafios, organizado por Craidy (2010), Educação em Prisões, organizado por Yamamoto et al (2010), Sociedade Cativa. Entre cultura escolar e cultura prisional: Uma incursão pela ciência penitenciária, produzido por Vasquez (2010); Espaço da Prisão e suas Práticas Educativas: Enfoques e perspectivas contemporâneas, organizado por Lourenço e Onofre (2011).

Também corroborou com a temática, Neves (2011) ao evidenciar que no início do século $\mathrm{XX}$, a oferta da atividade física como prática do tratamento penitenciário passou a ser utilizada como uma forma de tratamento disciplinar ao homem criminoso, já que o crime estava associado à hereditariedade, degeneração e higiene. Por isso, a atividade física era utilizada para controlar, moralizar e disciplinar o corpo biológico e social do homem criminoso, contribuindo com o debate do que se entendia, na época, sobre ressocialização.

É importante ressaltar que a prática da atividade física/exercício físico passou a ser usada como uma técnica de tratamento ao sujeito preso, a partir do período em que se instituiu a pena privativa da liberdade, aquela que restringe, com maior ou menor intensidade, a liberdade do condenado. Ele permanece em uma prisão por um determinado tempo, com o fim de moralizar e controlar o corpo do encarcerado, sendo também a prática de atividade física considerada proposta de ressocialização.

Neves (2011) exemplifica algumas escolas, que entre os séculos XIX e $\mathrm{XX}$, tinham em seus programas educacionais a prática da atividade física no contexto da educação penitenciária, como: Escolas de primeiras letras da Casa de Correção do Rio de Janeiro e Presídio de Fernando de Noronha, Escolas da Casa de Correção do Rio Grande do Sul e Penitenciária de Florianópolis.

\footnotetext{
${ }^{3}$ Para saber sobre os eventos, trabalhos e temas discutidos no Projeto Educando para Liberdade, vide: UNESCO. Seminário Nacional pela Educação nas Prisões: Significados e Proposições, 2006; UNESCO. Educando para a Liberdade: Trajetória, debates e proposições de um projeto para a educação nas prisões brasileiras, 2007; UNESCO. Educación en Prisiones en Latinoamérica: Derechos, libertad y ciudadanía, 2008.
} 
Já no século XX, a educação penitenciária ${ }^{4}$ passou a ser ofertada por meio dos programas educacionais do Governo Federal, a exemplo, dos Projetos Minerva e João da Silva, Educação Integrada, dos projetos e ações do Movimento de Educação Básica da CNBB, do Movimento de Educação e também o Movimento Brasileiro de Alfabetização, com a participação de outras instituições, e em seguida pelos cursos ofertados pelo Ensino Supletivo e modalidade EJA (JULIÃO, 2007; VASQUEZ, 2010; ABREU, 2008; PENNA, 2007; MOREIRA, 2008).

\subsection{Educação Penitenciária na atualidade}

No início do século XXI, intensificaram-se os debates sobre a educação penitenciária no Brasil, pois os Estados e o Distrito Federal estavam elaborando as primeiras versões dos Planos Estaduais de Educação para os Sistemas Prisionais.

Assim, para que se efetive a implementação de políticas públicas à educação penitenciária, é imprescindível a realização de audiências públicas, pesquisas e eventos científicos, com a participação de integrantes de grupos de pesquisa, comissões e sociedade civil organizada para se discutir os problemas específicos de cada Estado, visando acompanhar os desdobramentos de ações planejadas, tendo em vista a Lei no $7.626 / 11$, que instituiu o Plano Estratégico de Educação no âmbito do Sistema Prisional - PEESP (BRASIL, 2011).

Em um importante documento que trata do direito humano à educação, temos a seguinte consideração, quanto ao diagnóstico da educação penitenciária no mundo:

Faltam diagnósticos e informações consolidadas que permitam traçar um panorama preciso sobre a situação da educação prisional no mundo. Estima-se que menos de um terço da população privada de liberdade no planeta tenha acesso a algum tipo de atividade educativa no ambiente prisional o que, em grande parte, não significa o acesso à educação formal. Apesar de vários países contarem com legislações nacionais que garantem o direito das pessoas encarceradas à educação, a maioria está muito longe de concretizá-la nas unidades prisionais (CARREIRA, 2009, p. 25).

\footnotetext{
${ }^{4}$ Como no caso do Rio de Janeiro, Amapá e São Paulo.
} 
Entre os resultados deste trabalho, o qual teve como foco, visitas técnicas nas prisões do Pará, Pernambuco, Rio Grande do Sul, São Paulo e Distrito Federal, Carreira (2009) documentou que a educação para pessoas presas ainda é vista como um privilégio, pois a oferta de cursos de Educação Básica ainda é algo estranho no cotidiano do sistema penitenciário.

Neste contexto, muitos professores afirmaram sentir a unidade prisional como um ambiente hostil ao trabalho educacional, onde a educação se constitui, muitas vezes, em moeda de troca entre. Pois de um lado, há os gestores e agentes penitenciários, e do outro, os encarcerados, objetivando a manutenção da ordem disciplinar. Além disso, há um conflito cotidiano entre a garantia do direito à educação e o modelo vigente de prisão.

Ademais, o atendimento educacional é interrompido quando circulam boatos sobre a possibilidade de motins; na ocasião de revistas; como castigo ao conjunto das pessoas presas que integram uma unidade na qual ocorreu uma rebelião, ficando à mercê do entendimento e da boa vontade de direções e dos agentes penitenciários (CARREIRA, 2009).

\section{COMO SURGIU A PRODUÇÃO DESTE TEXTO?}

O presente estudo foi realizado, inicialmente, para apresentá-lo no I Encuentro Continental de Docentes y Organizaciones para la Educación en Contextos de Encierro, organizado pela Asociación de Docentes de Escuelas de Cárceles (ADEC), em Porto Iguazú e que ocorreu em 12 e 13 de maio de 2011, na Argentina.

Trata-se de um trabalho colaborativo desenvolvido a partir de pesquisa bibliográfica e documental, cujos dados incorporam também informações obtidas em entrevistas concedidas por Carlos José Pinheiro Teixeira (MEC/SECADI) e Roberto da Silva (FEUSP) ao Grupo de Estudos de Direitos Humanos e Educação Penitenciária - $(\text { GEDHEP })^{5}$, com aplicação de roteiro de entrevista encaminhado ao endereço eletrônico dos entrevistados, no período de 11 de abril a 04 de maio de 2011. As respostas dos entrevistados citadas no texto, respaldam-se na autorização de uso de trechos das entrevistas concedidas pelos entrevistados, por intermédio da primeira autora.

\footnotetext{
${ }^{5}$ Em 2011, este grupo de estudo não era cadastrado do Diretório de Grupos de Pesquisas do Conselho Nacional de Desenvolvimento Científico e Tecnológico (CNPq). Mas os seus membros (Eliane Leal Vasquez, Edmar Souza das Neves, Lucidea Portal e Zoar de OliveiraVasquez) reuniam-se no Semestre 2011.01, na Faculdade de Tecnologia do Amapá (FTA), na cidade de Macapá.
} 
O foco de análise deste estudo, baseia-se na Tabela de Acompanhamento de Execuções dos Recursos do Par Prisional relativa à Assistência Técnica e Financeira de Planos de Ações Articuladas (PAR Prisional), a legislação brasileira (BRASIL, 2009; 2010; 2011a; 2011b; 2011c), duas entrevistas realizadas pelo GEDHEP e demais referências sobre o tema, sendo o recorte temporal de 2005 a 2011.

\section{DISCUSSÃO DO RESULTADO}

Registramos a seguir, as considerações do entrevistado Carlos José Pinheiro Teixeira, que em 2011 exercia a função de coordenador nacional das ações de educação em prisões no Brasil e trabalhava na SECADI/MEC, com relação à pergunta: Como surgiu o Projeto Educando para Liberdade, nos esclareça sobre a sua coordenação, finalidade, ações pretendidas, recursos financeiros para execução do seu cronograma de ações e tempo de duração?

Surgiu a partir da provocação do Departamento Penitenciário Nacional do Ministério da Justiça ao Ministério da Educação em 2004. Como conseqüência foi assinado Protocolo de Intenções entre estes dois Ministérios e criado grupo de trabalho com a participação de representantes das secretarias de estaduais de educação e dos órgãos responsáveis pela administração penitenciária, com o apoio da UNESCO. Este grupo definiu os eixos que organizaram as ações e a realização de seminários regionais e nacionais para a definição de diretrizes para a oferta de educação nos estabelecimentos penais. Paralelo a isto, o MEC transferiu recursos para os Estados realizarem ações de formação dos profissionais envolvidos na oferta de educação. O Projeto Educando para a Liberdade que teve início em 2005, foi finalizado com seus objetivos alcançados em 2010 (Carlos José Pinheiro Teixeira, 2011).

Nesse contexto, o Projeto Educando para Liberdade reuniu uma série de estratégias para a inclusão da população carcerária nas políticas de educação de jovens e adultos do Ministério da Educação, com a aprovação das Diretrizes nos Conselhos Nacional de Educação e de Políticas Criminais e Penitenciárias, a saber:

1. Financiamento via Fundo de Manutenção e Desenvolvimento da Educação Básica e de Valorização dos Profissionais da Educação - FUNDEB; 2. Distribuição dos livros pelo Programa Nacional do Livro Di- 
dático - PNLD; 3. Merenda Escolar pelo Programa Nacional de Alimentação Escolar- PNAE; 4. Plano Nacional de Formação de professores; 5. Assistência Técnica e Financeira via Plano de Ações Articuladas - PAR, com recursos para elaboração dos Planos Estaduais, formação de profissionais e aquisição de acervos literários (Carlos José Pinheiro Teixeira, 2011).

A seguir, apresentamos a segunda questão do instrumento de coleta de dados: Considerando que resultados de ações do Projeto Educando para Liberdade implicou na aprovação das diretrizes nacionais para educação em prisões, qual a sua importância no contexto das políticas de educação de jovens e adultos?

As diretrizes são marco normativo que orientam a oferta de educação nas prisões. Marco este que era reivindicado por todos os profissionais que atuam nesta área. O processo de elaboração dos planos estaduais de educação para os sistemas prisionais ainda não foi concluído. Em função da publicação das diretrizes nacionais e do interesse dos Conselhos Estaduais se manifestarem sobre a matéria, o prazo de finalização destes planos passou para o final de 2011. Os planos elaborados com a participação de diretores de estabelecimentos penais, agentes e técnicos penitenciários, diretores de escolas, professores, internos e entidades da sociedade civil organizada são importantes para ampliação da oferta da educação nas prisões. Outra condição importante é que os planos sejam amplamente divulgados. Não podemos esquecer que estes planos devem ser integrados ao Plano Estadual de Educação que serão provocados com a aprovação do Plano Nacional de Educação (Carlos José Pinheiro Teixeira, 2011).

Estas considerações nos permitem compreender que o prazo para encaminhamento ao Ministério da Educação das primeiras versões dos Planos Estaduais de Educação para os Sistemas Prisionais - PEESP, pelos Estados e Distrito Federal passou para o final de 2011, devendo suas metas intregarem-se aos Planos Estaduais de Educação - PEE, e logo à política educacional brasileira.

Carlos José Pinheiro Teixeira (2011) também respondeu a seguinte questão: O Ministério da Justiça pretende dar publicidade dos PEESP à sociedade brasileira? "Sim, a ideia é dar ampla divulgação dos planos estaduais, disponibilizando-os na versão eletrônica. Além disso, temos a intenção de publicar uma apresentação destes planos com considerações sobre os documentos". 
E por último, questionou-se sobre: Qual a sua avaliação acerca da articulação entre o Ministério da Educação e Ministério da Justiça, grupos de pesquisas e outros segmentos da sociedade brasileira para se dá visibilidade a educação penitenciária no Brasil?

A articulação entre os dois Ministérios se mostrou exitosa em todas as suas dimensões. A marca sempre foi à realização de ações integradoras e articuladas e até hoje o planejamento é feito de forma integrada. A temática ainda é pouco discutida na academia, mas é fácil perceber um aumento importante na produção acadêmica após o surgimento do Projeto Educando para a Liberdade. Uma produção foi apresentada pela UFSCAR que publicou, em 2007, o livro Educasaão Escolar entre as Grades (Carlos José Pinheiro Teixeira, 2011).

E ainda, ele prossegue:

É esperada para o primeiro semestre de 2011, nova publicação da UFSCAR. Desta vez, com artigos de pesquisadores do Brasil e Argentina. Vale salientar a participação de pesquisadores no Seminário Internacional de Educação em Prisões: Convergências e Perspectiva, promovido pelo MEC/MJ em junho de 2010, com o apoio da Organização dos Estados Iberoamericanos (OEI). Por último, registro os esforços dos países na reestruturação da Rede Latino Americana de Educação em Prisões (Carlos José Pinheiro Teixeira, 2011).

Teixeira refere-se à produção sobre a educação penitenciária do Grupo de Pesquisa Práticas Sociais e Processos Educativos, vinculado ao Centro de Educação e Ciências Humanas da Universidade Federal de São Carlos (USFCAR $)^{6}$, bem como mencionou de forma implícita, a previsão da publicação do livro: O Espaço da Prisão e suas Práticas Educativas: Enfoques e Perspectivas Contemporâneas (LOURENÇO, ONOFRE, 2011).

Roberto da Silva (2011) esclareceu que seu grupo de pesquisa ${ }^{7}$ contribuiu com o processo de elaboração das primeiras versões dos planos estaduais de educação para os sistemas prisionais, o que se observa em um trecho de sua entrevista, em que ele fala:

\footnotetext{
${ }^{6}$ Liderado pelas pesquisadoras Petronilha Beatriz Gonçalves e Silva, e, Maria Waldenez de Oliveira, conforme informações obtidas no website: http://dgp.cnpq.br/dgp/espelhogrupo/ 2454260605293332 .

${ }^{7}$ Grupo de Estudos e Pesquisas sobre Educação em Regimes de Privação da Liberdade (GEPÊPrivação).
} 
O GEPÊPrivação elaborou previamente uma metodologia para construção dos planos estaduais. Esta metodologia foi testada com sucesso no Mato Grosso do Sul, estado que apresentava melhores condições naquele momento para a testagem. Depois a mesma foi aplicada em dois outros estados e apresentada à OEI, DEPEN e SECAD em dezembro de 2010, com o objetivo de socializá-la com grupos de pesquisas de outros estados. Os planos são de propriedade de cada estado e se tornarão públicos depois das aprovações pelos órgãos técnicos das Secretarias de Educação e da Administração Penitenciária. Em todos os planos até agora elaborados consideram-se a articulação entre a LDB e a LEP, entre ensino e trabalho e a elevação da escolaridade tanto da população carcerária, quanto de agentes penitenciários, além da formação continuada para os profissionais da educação. Colaborei com os estados de Mato Grosso do Sul, Santa Catarina e Mato Grosso. Participei das discussões no Rio de Janeiro, Bahia, Rondônia e Acre (Roberto da Silva, 2011).

Portanto, neste trecho da entrevista destacou-se a atuação do pesquisador Roberto da Silva, na elaboração do Plano Estadual de Educação em Estabelecimentos Penais do Mato Grosso do Sul, de Santa Catarina e Mato Grosso (SILVA, 2010; SILVA; MOREIRA; ANDRADE, 2010; SILVA; ANDRADE; MOREIRA. 2010), os quais já em 2010 estavam concluídos, e no ano seguinte, estes estavam disponíveis em versão digital no Website do Ministério da Justi$\mathrm{ça}^{8}$.

De acordo com a análise de dados da Tabela de Acompanhamento de Execuções dos Recursos do Par Prisional (BRASIL, 2011a), relativa à Assistência Técnica e Financeira do Plano de Ações Articuladas (PAR Prisional) foi possível constatar que até maio de 2011, somente 14,88\% das Unidades Federadas concluíram a elaboração das primeiras versões do PEESP (Figura 1).

A Figura 1 sintetiza o processo de elaboração das primeiras versões dos Planos Estaduais de Educação para os Sistemas Prisionais.

\footnotetext{
${ }^{8}$ Vide: MINISTÉRIO DA JUSTIÇA. Normativos - Educação nas prisões, disponível em: http://www.justica.gov.br/seus-direitos/politica-penal/politicas-2/educacao-no-sistema-prisional/normativos.
} 
Figura 1 - Execução dos Recursos do PAR Prisional

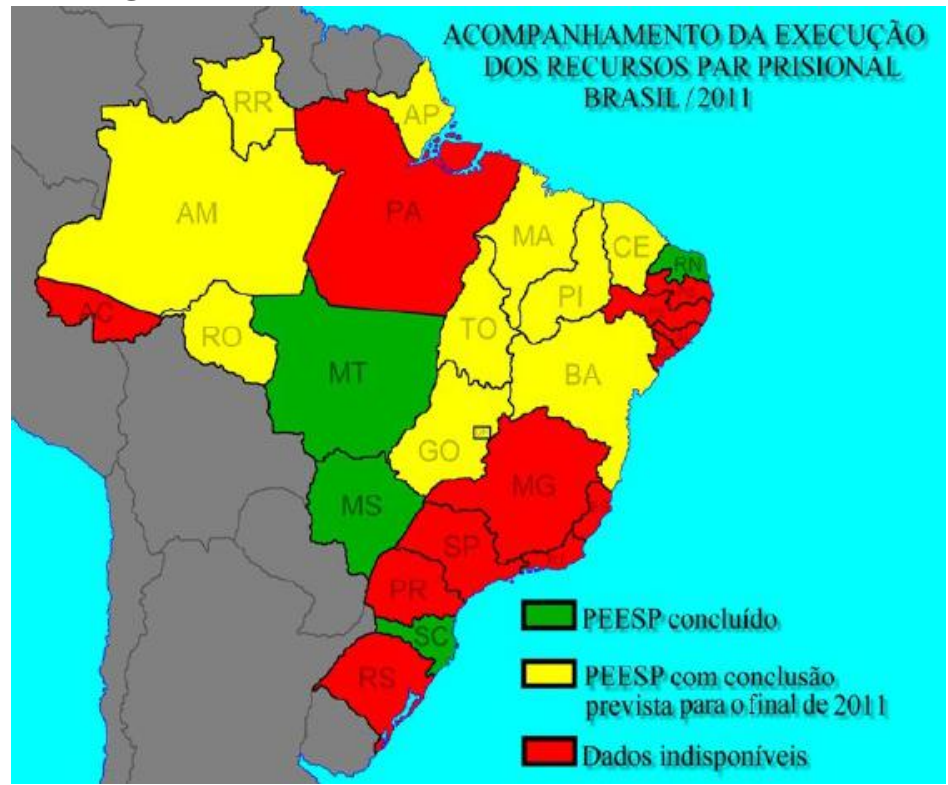

Fonte: Mapa elaborado por Zoar de Oliveira Vasquez, com base no documento da SECADI/MEC (BRASIL, 2011a).

Comparando os dados da Tabela de Acompanhamento de Execuções dos Recursos do Par Prisional (BRASIL, 2011a) e as informações da Figura 1, pode-se concluir que até maio de 2011, apenas os Estados de Santa Catarina, Rio Grande do Norte, Mato Grosso e Mato Grosso do Sul concluíram a elaboração das primeiras versões dos PEESP.

Além disso, os Estados de Paraíba, Roraima, Tocantins, Goiás, Rondônia, Amapá, Piauí, Ceará, Amazonas, Bahia e Maranhão, e incluído o Distrito Federal (Brasília) estavam previstos concluir os seus planos até o final de 2011. Por outro lado, quanto aos demais Estados, não havia nenhuma informação no documento analisado e que orientou a produção da Figura 1.

Nesse trabalho apresentamos uma revisão histórica da educação penitenciária no Brasil para situar sua discussão na atualidade como uma pauta das políticas educacionais e de execução penal, ligadas ao Ministério da Educação e Ministério da Justiça. No período de 2005 a 2010, esses ministérios por intermédio do Projeto Educando para Liberdade, provocaram a realização de seminários regionais e nacionais em que se debateram os problemas da educação penitenciária, como uma questão que envolve também a política de execução penal e a política educacional. 
A referida temática evidenciou-se nos debates e ações desenvolvidas a partir de 2005, quando no Ministério da Educação, foi criado a Secretaria de Educação Continuada, Alfabetização e Diversidade (SECAD) e que contou com a adesão dos órgãos estaduais, secretarias de estados, pesquisadores e outros segmentos da sociedade brasileira.

Em termos concretos, o que ocorreu de 2005 até 2011, foi a aprovação da Resolução CNPCP n³/2009 e CNE/CEB nº 2/2010, respectivamente, do Conselho Nacional de Política Criminal e Penitenciária, e Conselho Nacional de Educação que normatizaram as diretrizes nacionais para oferta da educação às pessoas privadas de liberdade, como ainda, a aprovação da Lei no 12433/2011, que dispõe sobre a remição de parte do tempo de execução da pena por estudo ou por trabalho e do Decreto $\mathrm{n}^{\circ} 7626 / 2011$ que trata do PEESP (BRASIL, 2009; 2010; 2011b; 2011c).

\section{CONSIDERAÇÕES FINAIS}

A partir da análise da Tabela de Acompanhamento de Execução dos Recursos do Par Prisional do MEC/SECAD (BRASIL, 2011a) constatamos que até maio de 2011, 14,88\% dos Estados concluíram a elaboração das primeiras versões dos PEESP, respectivamente, Santa Catarina, Rio Grande do Norte, Mato Grosso e Mato Grosso do Sul.

Além disso, 44,44\% dos Estados, como Paraíba, Roraima, Tocantins, Goiás, Rondônia, Amapá, Piauí, Ceará, Amazonas, Bahia e Maranhão e incluído o Distrito Federal estavam previstos concluir os seus PEESP até o final de 2011. Enquanto que 40,74\% dos Estados, isto é, Pará, Acre, Paraiba, Pernambuco, Alagoas, Sergipe, Rio Grande do Sul, Paraná, São Paulo, Rio de Janeiro, Minas Gerais e Espírito Santo não tinham dados disponíveis acerca dos PEESP até maio de 2011, no documento analisado.

Esses dados estatísticos revelam que, em 2011, os Ministérios da Educação e Justiça, Secretarias de Estado da Educação e Segurança Pública articularam-se para iniciar a formulação das políticas educacionais no âmbito do sistema prisional. Este fato também é comprovado pela primeira etapa do planejamento realizado pelos Estados e Distrito Federal, quanto à elaboração das primeiras versões dos PEESP, trabalho que foi desenvolvido, considerando que cada Estado desejava captar recurso financeiro para aplicar na execução de projetos destinados à população carcerária, servidores públicos da área da Educação e Segurança Pública que trabalham com a formação escolar de adultos presos. 


\section{REFERÊNCIAS}

ABREU, A. A. Educação entre Grades: um estudo sobre educação penitenciária no Amapá.. 2008. Dissertação (Mestrado em Educação) - Universidade Federal de São Carlos, São Carlos, 2008.

AÇÃO EDUCATIVA. O acesso à educação escolar nas prisões: direito ou privilégio? Boletim OPA, São Paulo, Ano III, n. 24, p. 1-2, 2006.

BRASIL. MEC/SECAD. Anexo I - Tabela de Acompanhamento de Execução dos Recursos do Par Prisional. Brasília, 2011a.

. Lei no 7210/84. Institui a Lei de Execução Penal. In: GOMES, L. F., (Org.). Constituição Federal, Código Penal, Código de Processo Penal. 8.ed. São Paulo: RT, 2006. Vol. 2.

. Decreto no 678 de 06 de julho de 1850. Dá Regulamento para a Casa de Correcção do Rio de Janeiro. In: ROIG, R. D. E. Direito e prática da execução penal no Brasil. Rio de Janeiro: Revan, 2005. p. 182-209.

Decreto no 3403 de 11 de fevereiro de 1865. Manda executar o regulamemto para o Presidio de Fernando de Noronha. Disponível em: < $\underline{\text { http:// }}$ www2.camara.leg.br/legin/fed/decret/1824-1899/decreto-3403-11-fevereiro1865-554542-publicacaooriginal-73167-pe.html>. Acesso: 14 dez. 2018.

. Decreto nº 8386 de 14 de janeiro de 1882. Dá novo Regulamento para a Casa de Correcção da Côrte. In: ROIG, R. D. E. Direito e prática da execução penal no Brasil. Rio de Janeiro: Revan, 2005. p. 218-257.

. Decreto no 3647 de 23 de abril de 1900. Dá novo Regulamento á Casa de Correcção da Capital Federal. In: ROIG, R. D. E. Direito e prática da execução penal no Brasil. Rio de Janeiro: Revan, 2005. p. 258-292.

. CONSELHO NACIONAL DE POLÍTICA CRIMINAL E PENITENCIÁRIA. Resolução CNPCP no 14 de 11 de novembro de 1994. Resolve fixar as Regras Mínimas para o Tratamento do Preso no Brasil. Disponível em: < $\underline{\text { http://www.justica.gov.br/seus-direitos/politica-penal/politicas- }}$ 2/mulheres-1/anexos-projeto-mulheres/resolucao-no-14-de-11-de-novembrode-1994.pdf/view>. Acesso: 14 dez. 2018.

. MINISTÉRIO DA JUSTIÇA. CONSELHO NACIONAL DE POLÍTICA CRIMINAL E PENITENCIÁRIA. Resolução CNPCP $\mathbf{n}^{\mathbf{o}}$ 3/2009. Dispõe sobre as Diretrizes Nacionais para a Oferta de Educação nos 
estabelecimentos penais. Disponível em: $<$ http://www.justica.gov.br/seusdireitos/politica-penal/politicas-2/educacao-no-sistema-prisional/ resolucao cnpcp 3 2009-2.pdf > . Acesso: 14 dez. 2018.

MINISTÉRIO DA EDUCAÇÃO. CONSELHO NACIONAL DE EDUCAÇÃO CÂMARA DE EDUCAÇÃO BÁSICA. Resolução CNE/ CEB $n^{\circ} 2 / 2010$. Dispõe sobre as Diretrizes Nacionais para a oferta de educação para jovens e adultos em situação de privação de liberdade nos estabelecimentos penais. Disponível em: < $\underline{\text { http://www.justica.gov.br/seus-direitos/poli- }}$ tica-penal/politicas-2/educacao-no-sistema-prisional/ resolucao cne 2 2010.pdf/view>. Acesso: 14 dez. 2018.

. Lei $\mathbf{n}^{\circ} \mathbf{1 2 . 4 3 3}$, de 29 de junho de 2011b._Altera a Lei no 7.210, de 11 de julho de 1984 (Lei de Execução Penal), para dispor sobre a remição de parte do tempo de execução da pena por estudo ou por trabalho. Disponível em: <http://www.planalto.gov.br/CCivil_03/_Ato2011-2014/2011/Lei/ L12433.htm >. Acesso: 14 dez. 2018.

Decreto $\mathbf{n}^{\mathbf{0}}$ 7.626/2011c. Institui o Plano Estratégico de Educação no âmbito do sistema prisional. Disponível em: $<\underline{\text { http://portal.mec.gov.br/index.php? }}$ option $=$ com content\&view $=$ article\&id $=17460 \&$ Itemid $=817>$. Acesso: 14 dez. 2018.

CARRREIRA, D. Relatoria nacional para o direito humano à educação: educação nas prisões brasileiras. São Paulo: Plataforma DHESCA Brasil, 2009.

CARVAlHeiro, M. S. Políticas Públicas Educacionais da EJA aplicadas nas Unidades Prisionais - Pós 1995. 2010. Disponível em: < http://www.diaadiaeducacao.pr.gov.br/diaadia/diadia/arquivos/File/conteudo/ artigos teses/2010/Pedagogia/apolpubeja.pdf>. Acesso: 14 dez. 2018.

FLEURY, A. A. P.; VILLAÇA, J. P.; PESTANA, F. R. Relatorio da Commissão Inspectora da Penitenciaria, S. Paulo, 12 de Novembro de 1885. In:

RELATORIO apresentado à Assembléa Legislativa Provincial de São Paulo pelo presidente da provincia, João Alfredo Corrêa de Oliveira. São Paulo: Typ. a Vapor de Jorge Seckler \& C, 1886.

FOUCAUlT, M. Vigiar e Punir. Nascimento da Prisão. Trad. de Lígia. M. Pondé Vassalo. Petrópolis: Vozes, 1977. 
IRELAND, T. D. Anotações sobre a educação em prisões: direito, contradições e desafios. In: CRAIDY, C. M. (Org.). Educação em Prisões: direito e desafio. Porto Alegre: Ed. UFRGS, 2010, p. 23-35.

JAGUARY; TOLENTINO, A. N.; FLEURY, A. A. P.; GOUVÊA, L. B.; PINTO, J. A. N. Relatorio da Commissão Inspectora da Casa de Correcção da Corte. Rio de Janeiro, 15 de Fevereiro de 1874. In: RELATORIO apresentado à Assembléa Geral Legislativa na Terceira Sessão da Décima Quinta Legislatura pelo Ministro e Secretário de Estado dos Negócios da Justiça, Dr. Manoel Antônio Duarte de Azevedo. Rio de Janeiro: Typographia Americana, 1874.

JULIÃO, E. F. Política pública de educação penitenciária: contribuição para o diagnóstico da experiência do estado do rio de janeiro. 2003. Dissertação (Mestrado em Educação) - Pontifícia Universidade Católica do Rio de Janeiro, Rio de Janeiro, 2003.

. Os Sujeitos da Educação de Jovens e Adultos Privados de Liberdade: Questões sobre a diversidade. Boletim do Programa para o Futuro, Brasília, n. 6, p. 22-28, Mai. 2007.

LOURENÇO, A. S.; ONOFRE, E. M. C. (Org.). O espaço da prisão e suas práticas educativas: enfoques e perspectivas contemporâneas. São Carlos: EdUFSCar, 2011. v. 1.

MENEZES, M. V. A Escola Correcional do Recife. In: MAIA, C. N.; SÁ NETO, F.; COSTA, M. BRETAS, M. L. (Org.). História das prisões no Brasil. Rio de Janeiro: Rocco, 2009, p. 249-275, Vol. 2.

MINISTÉRIO DA JUSTIÇA. Normativos - Educação nas prisões. Disponível em: < http://www.justica.gov.br/seus-direitos/politica-penal/politicas2/educacao-no-sistema-prisional/normativos >. Acesso: 14 dez. 2018.

Planos Estaduais de Educação nas Prisões. Disponível em:

$<$ http://www.justica.gov.br/seus-direitos/politica-penal/politicas-2/educacaono-sistema-prisional/planos-estaduais-de-educacao-nas-prisoes/Planos $>$. Acesso: 14 dez. 2018.

MORAES, E. Prisões e instituições penitenciarias no Brazil. Rio de Janeiro: Liv. Ed. Cons. Cândido de Oliveira, 1923. 
MOREIRA, F. A. A política de educação de jovens e adultos em regimes de privação da liberdade no estado de São Paulo. 2008. Dissertação (Mestrado em Educação) - Universidade de São Paulo, São Paulo, 2008.

NEVES, E. S. A atividade física no sistema prisional brasileiro: algumas iniciativas da educação penitenciária no início do século xx. 2011. Dissertação (Mestrado em Educação Física) - Universidade São Judas Tadeu, São Paulo, 2011.

. Tempo-Memória e Educação no Presídio Ilha de Fernando de Noronha: Aspectos históricos à luz da ciência penitenciária. In: BAPTISTA, A. M. H.; ROGGERO, R.; MAFFRA, J. (Org.). Tempo-Memória: perspectivas em Educação. São Paulo: BT Acadêmica, 2015. p. 111-123.

ONOFRE, E. M. C. (Org.). Educação escolar entre as grades. São Carlos: EdUFSCar, 2007.

PENNA, M. G. O. O exercício docente por monitores-presos e o desenvolvimento do processo formativo. In: ONOFRE, E. M. C. (Org.). Educação escolar entre as grades. São Carlos: EdUFSCar, 2007, p. 77-91.

SANTOS, M. S. Os Porões da República: A barbárie nas prisões da Ilha Grande. 1894-1945. Rio de Janeiro: Garamond, 2009.

SILVA, R. Plano Estadual de Educação em Estabelecimentos Penais do Mato Grosso do Sul. Campo Grande, 2010.

SILVA, R.; MOREIRA, F. A.; ANDRADE, B. C. Plano Estadual de Educação em Estabelecimentos Penais do Estado de Santa Catarina. Florianópolis, 2010.

SILVA, R.; ANDRADE, B. C.; MOREIRA, F. A._Plano Estadual de Educação em Estabelecimentos Penais do Estado de Mato Grosso. Cuiabá, 2010.

UNESCO. Seminário Nacional pela Educação nas Prisões: Significados e Proposições. Brasília: UNESCO/MJ/ME, 2006.

. Educando para a liberdade: trajetória, debates e proposições de um projeto para a educação nas prisões brasileiras. Brasília: UNESCO/MJ/ME, 2007.

Educación en prisiones en latinoamérica: derechos, liberdad y ciudadanía. Brasília: UNESCO, 2008. 
VASQUEZ, E. L. Ciência penitenciária no Brasil império: disciplinar para construir a imagem da nação civilizada. 2013. Tese (Doutorado em História da Ciência) - Pontifícia Universidade Católica de São Paulo, São Paulo, 2013.

Sociedade cativa. Entre cultura escolar e cultura prisional: uma incursão pela ciência penitenciária. Rio de Janeiro: CBJE, 2010. VASQUEZ, E. L.; NEVES, E. S. Plano Estadual de Educação nas Prisões de Roraima. Boa Vista, 2012.

YAMAMOTO, A.; GONÇALVES, E.; GRACIANO, M.; LAGO, N. B.; ASSUMPÇÃO, R. (Org). Educação em Prisões. São Paulo: Cereja/Alfasol, 2010. 